\title{
Systematics and conservation of the hook-billed kite including the island taxa from Cuba and Grenada
}

\author{
J. A. Johnson ${ }^{1,2}$, R. Thorstrom ${ }^{1} \&$ D. P. Mindell ${ }^{2}$ \\ 1 The Peregrine Fund, Boise, ID, USA \\ 2 Department of Ecology \& Evolutionary Biology, University of Michigan Museum of Zoology, Ann Arbor, MI, USA
}

\section{Keywords}

phylogenetics; coalescence; divergence; conservation; cryptic species; Chondrohierax.

\author{
Correspondence \\ Jeff A. Johnson, Department of Ecology \& \\ Evolutionary Biology, University of Michigan \\ Museum of Zoology, 1109 Geddes Avenue, \\ Ann Arbor, MI 48109, USA. \\ Email: jeffaj@umich.edu
}

Received 2 December 2006; accepted 20 April 2007

doi:10.1111/j.1469-1795.2007.00118.x

\begin{abstract}
Taxonomic uncertainties within the genus Chondrohierax stem from the high degree of variation in bill size and plumage coloration throughout the geographic range of the single recognized species, hook-billed kite Chondrohierax uncinatus. These uncertainties impede conservation efforts as local populations have declined throughout much of its geographic range from the Neotropics in Central America to northern Argentina and Paraguay, including two island populations on Cuba and Grenada, and it is not known whether barriers to dispersal exist between any of these areas. Here, we present mitochondrial DNA (mtDNA; cytochrome $B$ and NADH dehydrogenase subunit 2) phylogenetic analyses of Chondrohierax, with particular emphasis on the two island taxa (from Cuba, Chondrohierax uncinatus wilsonii and from Grenada, Chondrohierax uncinatus mirus). The mtDNA phylogenetic results suggest that hook-billed kites on both islands are unique; however, the Cuban kite has much greater divergence estimates $(1.8-2.0 \%$ corrected sequence divergence) when compared with the mainland populations than does the Grenada hook-billed kite $(0.1-0.3 \%)$. Our findings support species status for the Cuban form, as Chondrohierax wilsonii, and subspecific status for the Grenada form. For mainland taxa, we do not find support for the currently recognized subspecies Chondrohierax uncinatus aquilonis in western Mexico, but we do find evidence for a genetic subdivision between populations in Central and South America, a difference previously unsuspected. The results of this study help identify conservation priorities associated with these unique Neotropical raptors. This information is of immediate interest because the Cuban kite has not been reliably seen since 1992, and $<50$ hook-billed kites currently inhabit Grenada.
\end{abstract}

\section{Introduction}

Our ability to diagnose evolutionary relationships among populations and provide accurate taxonomic recommendations has important conservation implications (Agapow et al., 2004; Mace, 2004; Purvis, Gittleman \& Brooks, 2005; Haig et al., 2006). It is well known that a universal definition of species is problematic because of the complex nature of speciation processes (see Hey et al., 2003; de Queiroz, 2005; Hey, 2006). Whether or not we are able to recognize differences between populations or species is dependent on the approach and the methods used to quantify the distinctiveness of each group (Hendry et al., 2000; Sites \& Marshall, 2004). Genetic methods have helped to resolve many phylogenetic and taxonomic uncertainties in which morphological characters among birds of prey show convergent similarity apparently due to a shared predatory or scavenging lifestyle (Bunce et al., 2005; Gamauf et al., 2005; Helbig et al., 2005; Johnson et al., 2005, 2006; Lerner \& Mindell, 2005).

The hook-billed kite Chondrohierax uncinatus is currently considered a monotypic genus, although it shows extreme intraspecific variation in bill size and color, facial color and plumage pattern and color throughout its Neotropical distribution, including two island populations on Cuba and Grenada (Fig. 1; Amadon, 1960, 1964; Smith \& Temple, 1982a; Ferguson-Lees \& Christie, 2001). This species has been described as having the greatest morphological variability of any bird of prey (Brown \& Amadon, 1968). This variability, at least for bill size, may be due to disruptive selection and reduction in intraspecific competition through different feeding niches based on distinct size-classes of snails, their primary prey (Smith \& Temple, 1982a; Galeotti \& Rubolini, 2004; Rueffler et al., 2006). The mechanism responsible for the variation in plumage coloration and pattern, although independent of bill size and geography is not well understood (see Smith \& Temple, 1982a). Males and females are typically light gray or brown, respectively, and barred or non-barred, to dark and almost solid black (i.e. melanistic phase) in both sexes, including varying numbers of tail bands (Ferguson-Lees \& Christie, 2001).

In contrast to the mainland populations, hook-billed kites occupying the islands of Cuba and Grenada show much less variability in bill and body size, along with 


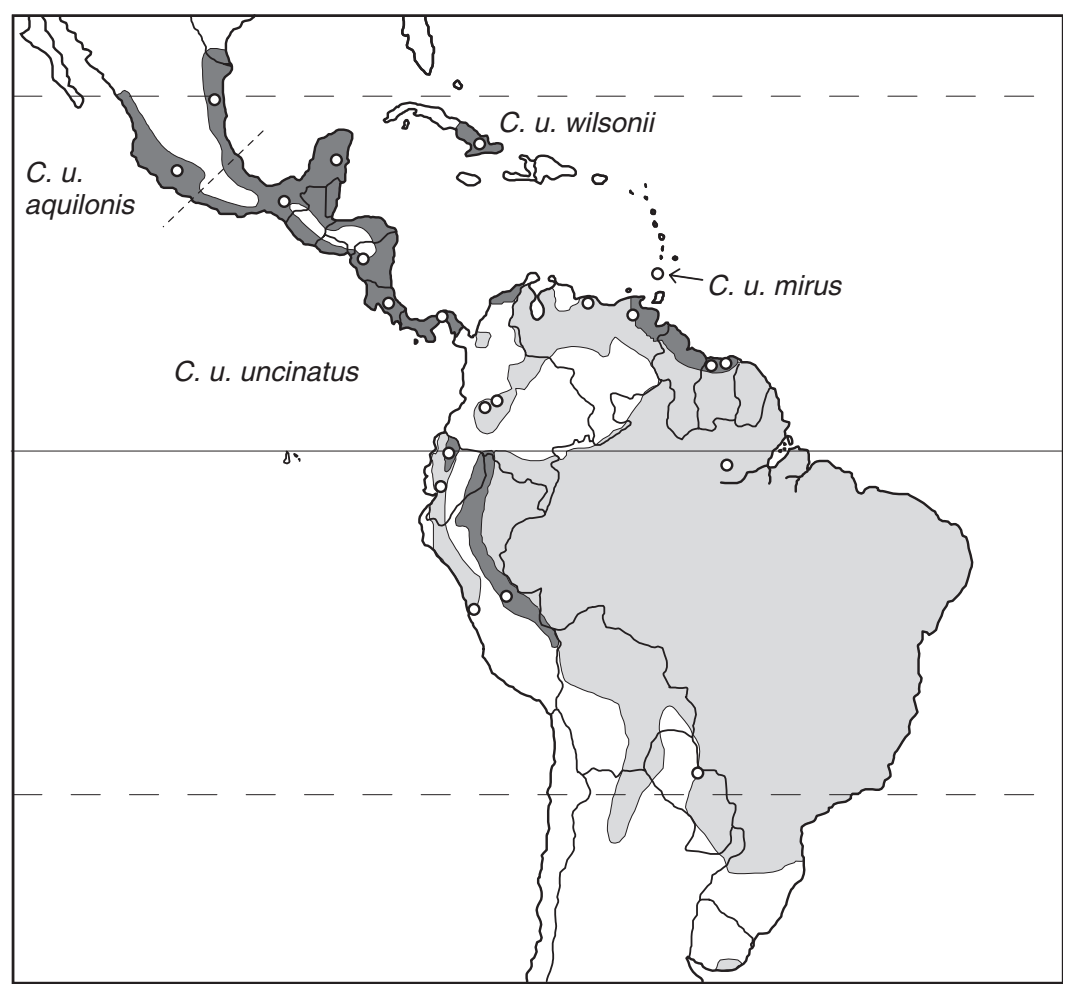

Figure 1 Geographic distributions of Chondrohierax uncinatus subspecies (after Ferguson-Lees \& Christie, 2001) and locations (white circles) for specimens used in this study. Lighter gray areas represent areas of more scattered distribution, and the dashed line in Mexico is the proposed boundary between the two subspecies Chondrohierax uncinatus aquilonis and Chondrohierax uncinatus uncinatus (Friedmann, 1934).

minimal variation in plumage coloration and pattern (Friedmann, 1934; Smith \& Temple, 1982a,b). Further, the melanistic phase for plumage coloration is absent in both island populations, and bill color, particularly the upper mandible, is yellow among hook-billed kites in Cuba as opposed to a black-colored bill observed elsewhere (Friedmann, 1934; Ferguson-Lees \& Christie, 2001). Similar to the mainland populations, variability in bill size, or lack thereof, in both Cuba and Grenada may be maintained by lower variability of snail size-classes on both islands (Smith \& Temple, $1982 a$ ), but more work is needed to better quantify these relationships.

Numerous taxonomic revisions have been proposed within this genus largely owing to the considerable variability in bill and plumage characters, along with their scarcity in the wild and the lack of life-history information. For example, the species Chondrohierax magarhynchus, later identified as a subspecies (Chondrohierax uncinatus immanis Friedmann, 1934), originally was described based on its large bill (>49 mm, culmen from cere) and restricted geographic distribution in the Andes of Venezuela, eastern Ecuador, Peru and Bolivia. However, additional hook-billed kites collected in Mexico were later described with similar-sized bills and the distinctiveness of this taxon was questioned (Hellmayr \& Conover, 1949) and subsequently not recognized (Amadon, 1964; Peters, 1979). Another subspecies, Chondrohierax uncinatus aquilonis, in north-western Mexico has also been designated, largely based on plumage differences, such as the width of white bars on feathers located on the upper parts of males (uncinatus, 1.5-3 mm; aquilonis, $\sim 5 \mathrm{~mm}$ ) including other characters such as plumage darkness (Friedmann, 1934; Peters, 1979). However, the taxonomic distinctiveness of the plumage characters for this subspecies has been questioned (Smith \& Temple, 1982a; del Hoyo, Elliot \& Sargatal, 1994), suggesting that all mainland hook-billed kites in Central and South America be recognized as a single subspecies (Chondrohierax uncinatus uncinatus).

For the island populations on Cuba and Grenada, fewer changes in taxonomy have been proposed, probably due to reduced variability in bill size and plumage coloration compared with mainland populations. Originally, hookbilled kites on Cuba were considered a separate species (Chondrohierax wilsonii; Peters, 1931; Friedmann, 1934) based on their yellow bill color, but later this taxon was identified as a subspecies (Chondrohierax uncinatus wilsonii; Amadon, 1960, 1964) due to overall similarities with other hook-billed kite taxa despite the distinctive yellow upper mandible. In some recent field guides, however, the Cuban kite has been treated as a distinct species (C. wilsonii; Raffaele et al., 1998; Garrido \& Kirkconnell, 2000 see also Stotz et al., 1996). Similar to Cuban hook-billed kites, those on Grenada are smaller in overall body size compared with the mainland populations, although this population does 
not possess any striking morphological features that separate it from other populations. The Grenada population is generally recognized as a subspecies of the hook-billed kite (Chondrohierax uncinatus mirus; Friedmann, 1934; Amadon, 1964; Peters, 1979).

Here, we apply phylogenetic and population genetics methods to determine evolutionary relationships among hook-billed kites. Our use of mitochondrial DNA (mtDNA) sequence data as an empirical measure of temporal isolation between populations (Hudson \& Coyne, 2002; Rosenberg, 2003) can help resolve taxonomic uncertainties, a vital aspect of species conservation (Johnson et al., 2005, 2006; see also Barker, 2002; Mace, 2004; Purvis et al., 2005). The Cuban kite has not been reliably observed in the wild since 1992 (Garrido \& Kirkconnell, 2000), and similarly, the number of individuals observed on Grenada are quite low, with only 15 territorial pairs observed over the past 6 years and estimates of total abundance at $c$. 40-50 individuals (Thorstrom, Massiah \& Hall, 2001; R. Thorstrom, unpubl. data).

\section{Methods}

\section{Taxon sampling, DNA extractions, amplification and sequencing}

To infer phylogenetic relationships among Chondrohierax taxa, a total of 32 individuals were sampled throughout a large portion of their geographic range (Fig. 1; Supplementary Material Table S1). Between two and 20 individuals were sampled from each of the recognized subspecies (Peters, 1979; Ferguson-Lees \& Christie, 2001), with the two island subspecies $C$. u. wilsonii from Cuba and mirus from Grenada represented by four and six individuals, respectively (see Supplementary Material Table S1). Based on results given by Lerner \& Mindell (2005), Leptodon cayanensis [accession numbers: AY987240 and AY987059 for cytochrome $B$ (cyt $B$ ) and NADH dehydrogenase subunit 2 (ND2), respectively], Elanoides forficatus (AY987241 and AY987060), Pernis apivorus (AY987242 and AY987061), Milvus milvus (AY994421 \& AY994464) and Milvus migrans (AY994433 and AY994476) were used as outgroup taxa for the phylogenetic analyses.

Total genomic DNA was extracted from blood or toe-pad tissue for museum specimens using a DNeasy Tissue Extraction Kit (Qiagen Inc., Valencia, CA, USA). All work with museum samples was conducted in a facility used only for ancient DNA work at the University of Michigan Museum of Zoology with protocols developed for ancient DNAs (Cooper \& Poinar, 2000; Gilbert et al., 2005). PCR amplifications were performed with Platinum Taq (Invitrogen, Carlsbad, CA, USA) using primers designed for mtDNA $\operatorname{cyt} B$ and ND2 (Supplementary Material Table S2). Potential contamination was monitored through the use of multiple extraction and PCR controls. PCR products were directly sequenced in both directions with ABI big dye terminator chemistry, resolved on an ABI 3730 automated sequencer (Applied Biosystems, Foster City,
CA, USA) and deposited in GenBank (accession numbers EF494383-EF494406).

\section{Phylogenetic and statistical analyses}

Sequences were aligned by eye, and no indels were observed in either $\operatorname{cyt} B$ or ND2. The number of haplotypes and haplotype diversity $(h)$ estimates for each population were calculated using the program DNASP version 4.00.6 (Rozas et al., 2003). We used both maximum parsimony (MP) and Bayesian inference using Markov chain Monte Carlo (MCMC) sampling approaches to reconstruct phylogenies. Analyses were conducted using samples for each locus separately and combined (cyt $B / \mathrm{ND} 2)$. MP trees were inferred using PAUP ${ }^{*}$ 4.0b10 (Swofford, 2003), and all character-state changes were equally weighted. All MP analyses were heuristic, with starting trees obtained by random taxa addition with 100 replicates and TBR branch swapping. Support values for clades were calculated from 1000 bootstrap replicates.

Bayesian analyses were implemented using MRBAYES version 3.1.2 (Ronquist \& Huelsenbeck, 2003). The best-fit model of evolution for each locus and codon nucleotide position was determined by Akaike information criterion (AIC) in Mr.ModelTest version 2.2 (Nylander, 2004). All Bayesian analyses were run with four chains for six million generations following a burn-in period of 20000 generations, with sampling performed every 200 generations. Four independent runs were conducted, and each converged on similar optimal log-likelihood scores and identical tree topologies. To further estimate phylogeographic structure among hook-billed kites, we also inferred a median-joining network (Bandelt, Forster \& Röhl, 1999) for the combined cyt $B$ and ND2 datasets using the program NETwORK version 4.2 (available at www.fluxus-engineering.com) with parameter $\varepsilon=0$ and using L. cayanensis as an outgroup.

Assuming no genetic subdivision within both Central and South America and defining populations as major haplotype clades based on our phylogenetic analyses (see 'Results'), we used the program IM to determine whether the lack of reciprocal monophyly observed between Central and South American populations was due to recent gene flow or incomplete lineage sorting following gene coalescence (see Hey \& Nielsen, 2004). To reduce the number of estimated parameters, and therefore increase the rate of parameter updates, our final runs with IM were conducted assuming symmetrical gene flow between Central and South America $\left(m_{\mathrm{CA}}=m_{\mathrm{SA}}\right)$ because preliminary runs while estimating both migration parameters separately indicated that migration rates were similar between the two populations. In our final analyses, three runs using the finite sites model (HKY; Hasegawa, Kishino \& Yano, 1985), with identical conditions, but with different random number seeds, were conducted. We used Metropolis coupling among five chains with five chain-swap attempts per step and a two-step heating increment to improve mixing and convergence among parameters. After a burn-in of 500000 steps, each run with the program IM was conducted with at least 20 
million steps with effective sample sizes (ESS) exceeding 500 for each parameter (with two of the three runs exceeding $\mathrm{ESS}=2400$ for each parameter). Here, we report our results from the longest run (396 million steps; minimum $\mathrm{ESS}=3700$ ) because each run provided similar results for the majority of parameters.

\section{Estimates of mutation rate and divergence times}

Because we do not have a good fossil calibration for estimating divergence times within the family Accipitridae, we applied a broad, generally supported avian mtDNA divergence rate for coding regions ranging from 1.6 to $5.0 \%$ change per million years (see Lovette, 2004). Therefore, the interpretation of these dates and their accuracy should be made with caution (see Ho \& Larson, 2006), and our use of these estimates is more for comparative purposes relative to the sequential timing of hook-billed kite population/taxon divergences. For the purposes of converting genetic divergences to the timing of divergences, we were not able to reject a hypothesis of clock-like behavior for our sequence dataset using a log-likelihood ratio test $(-\ln$ $L_{\text {clock }}=6584.41 ;-\ln L_{\text {non-clock }}=6570.21 ; 2 \Delta \ln L=28.39$; d.f. $=35 ; P>0.05)$.

\section{Results}

\section{Sequence characteristics and genetic diversity}

Based on cyt $B$ sequences (1039 bp) for 32 hook-billed kite individuals, 13 unique haplotypes were distinguished based on 25 variable sites (21 transitions and five transversions). For the complete mtDNA ND2 sequence data (1041 bp) with the same individuals as $\operatorname{cyt} B, 12$ unique haplotypes were observed based on 17 variable sites (16 transitions and one transversion). The combined analysis (2080 bp) from cyt $B$ and ND2 identified 19 unique haplotypes based on 42 variable sites among ingroup taxa. Based on geography, the Central $(n=9$; including Panama) and South $(n=13)$ American populations had five and 11 haplotypes, respectively, with haplotype diversities $(h \pm \mathrm{SE})$ of $0.722 \pm 0.053$ and $0.974 \pm 0.011$, respectively. For Cuba $(n=4)$ and Grenada $(n=6)$, both the number of haplotypes and haplotype diversity measures were lower, with two $(h=0.500 \pm 0.133)$ and one $(h=0.000)$ haplotypes observed for each island populations, respectively.

Nucleotide composition varied slightly between $\operatorname{cyt} B$ and ND2, with both loci displaying lower levels of guanine (12 and $10 \%$, respectively) and higher levels of cytosine (34 and $35 \%$ ) nucleotides than expected by chance. Tests for departure from homogeneity in base frequencies across taxa with and without uninformative mtDNA characters were not significant for loci analyzed separately or combined $\left(\chi^{2}\right.$, $P>0.05)$.

\section{Phylogenetic analyses}

The AIC identified the GTR + G model of sequence evolution for analyses of $\operatorname{cyt} B$ and ND2. When partitioned by codon position, GTR $+\mathrm{G}, \mathrm{HKY}+\mathrm{I}$ and HKY $+\mathrm{I}$ models were selected for each successive codon position (first, second and third, respectively) for $\operatorname{cyt} B$, and $\mathrm{HKY}+\mathrm{I}$, GTR $+\mathrm{I}$ and GTR $+\mathrm{G}$ models for ND2 codon positions. The same topology was found in both MP and Bayesian analyses irrespective of utilizing codon partitions for the Bayesian analyses or not; however, the partitioned analyses provided increased support indices at most nodes, and therefore, only the support indices while utilizing codon partitions are shown for the Bayesian results (Fig. 2).

With a few exceptions, MP and Bayesian analyses identified clades with high nodal support for three of the four general geographic areas sampled (i.e. Cuba, Central America and South America). In contrast, no resolution was observed relative to the currently recognized subspecies taxonomy for this genus, with the exception of the Cuban kite C. u. wilsonii; Fig. 2. The single unique haplotype sampled from Grenada (C. $u$. mirus) was observed within a larger South American clade (C. u. uncinatus), and the two hook-billed kites sampled from western Mexico (C. u. aquilonis) fall within a clade consisting of Central American birds identified as C.u. uncinatus. Further, although identified as the same subspecies (C. u. uncinatus), two hook-billed kites from Panama sampled from the Panama Canal area were observed within the South American clade, while a single sample from Colombia was sister to the rest of the Central American clade with high nodal support based on Bayesian posterior probability (Fig. 2). Using the GTR $+\mathrm{G}$ model of sequence evolution for both genes combined, the genetic divergence of the Cuban kite relative to the Central and South American populations ranged from 1.8 to $2.0 \%$ (i.e. $400000-1.25$ million years), and divergence estimates between both Central and South American populations, including those with Grenada, were much lower and ranged from 0.1 to $0.3 \%$ (i.e. 20000-190 000 years).

Similar to MP and the Bayesian analyses, the medianjoining network identified three separate haplotype clusters based on geography (i.e. Cuba and Central and South America), with two of the three hook-billed kites from Panama and an individual from Colombia intermixed between the Central and South American clusters (Fig. 3). Identifying each of the haplotypes based on this general geographic subdivision, no haplotypes are shared between Central and South America, including the single haplotype observed in Grenada, which forms a loop connected with a number of different haplotypes sampled in South America. The two haplotypes sampled from Cuba are quite distinct and require at least 29 nucleotide substitutions to connect with any hook-billed kite haplotype sampled elsewhere (Fig. 3).

\section{Demographic history (Central vs. South America)}

The coalescent method used in the program IM resulted in strong unimodal posterior distributions for most of our 




Figure 2 Phylogeny for Chondrohierax taxa based on complete mitochondrial cytochrome $B$ and NADH dehydrogenase subunit 2 genes. The topology shown is the Bayesian inference majority rule tree, which is congruent with MP analyses as well. MP bootstrap nodal support values $>50 \%$ are below the branches and Bayesian posterior probabilities are above. Branches at tips were collapsed if Bayesian posterior probability nodal support was below 0.50. The geographic sampling location is provided for each sample, and the number of samples is indicated in parentheses for locations represented by multiple individuals. Two additional outgroup taxa (Milvus milvus and Milvus migrans) are not shown.

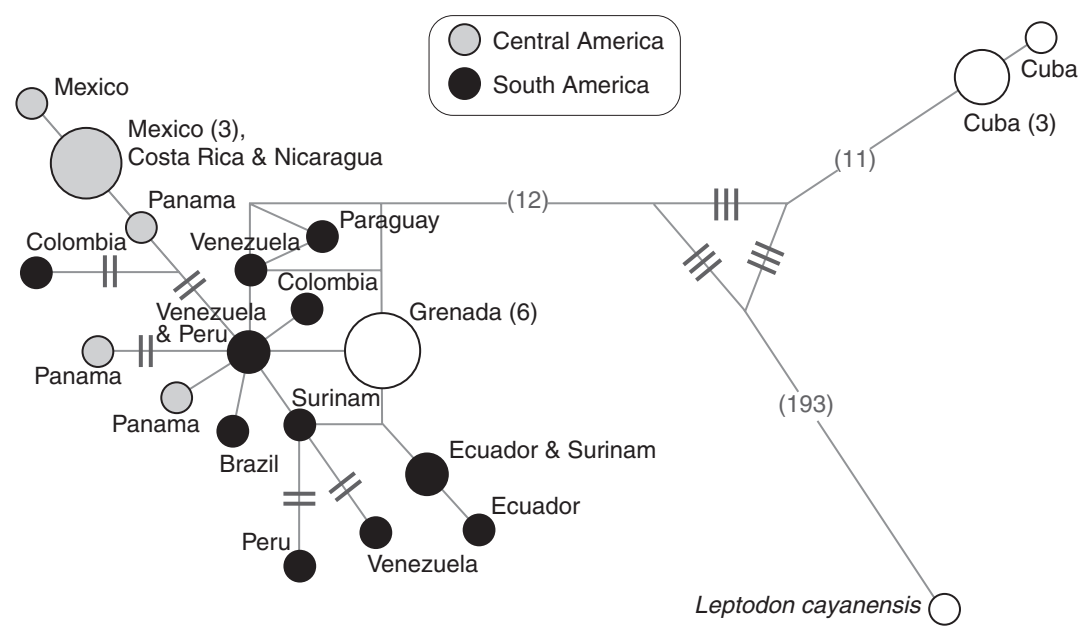

Figure 3 Median-joining network showing relationships among cytochrome $B$ and NADH dehydrogenase subunit 2 haplotypes sampled from Chondrohierax. Circle size is proportional to the number of individuals with that haplotype, and geographic sampling locations are given for each haplotype, with multiple individuals indicated in parentheses. Dash marks along branches indicate nucleotide substitutions, with those greater than three indicated by the number in parentheses along the branch.

parameter estimates (Fig. 4). However, the upper portion of the posterior distribution for South America female effective size $\left(\theta_{\mathrm{SA}}=2 N_{\mathrm{ef}} \mu\right.$, where $N_{\text {ef }}$ is the female effective population size and $\mu$ is the mutation rate per locus per year) approached zero very slowly, even after substantially increasing our priors for this parameter (i.e. 800, 3000 and 
(a)

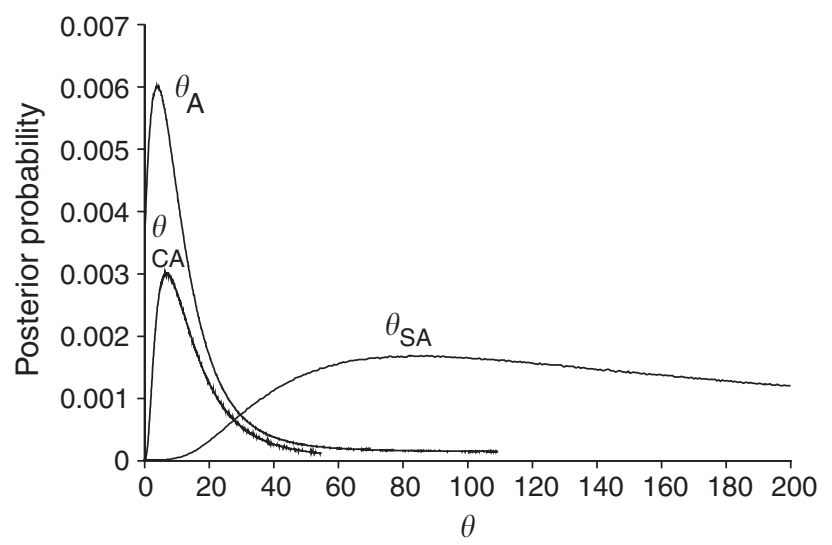

(c)

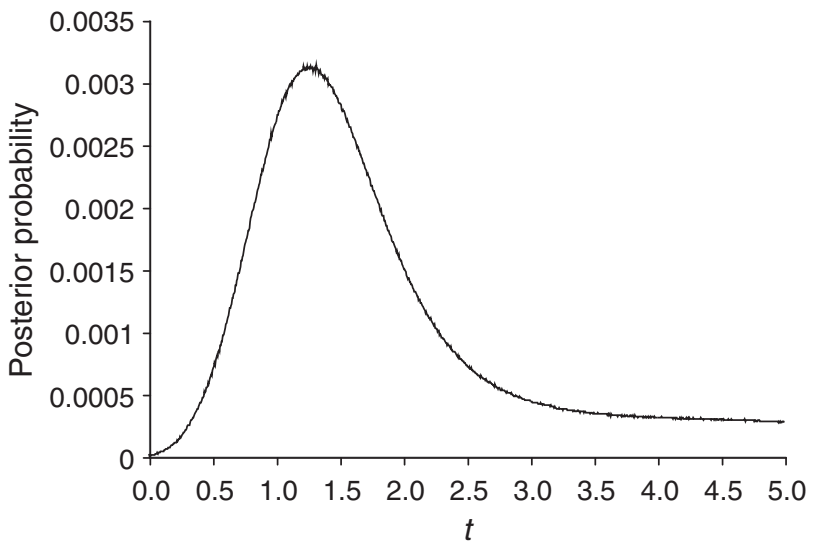

(b)

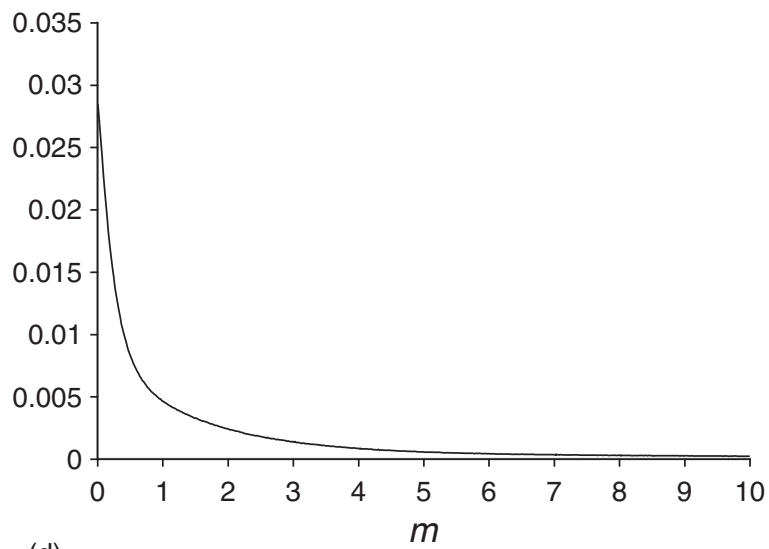

(d)

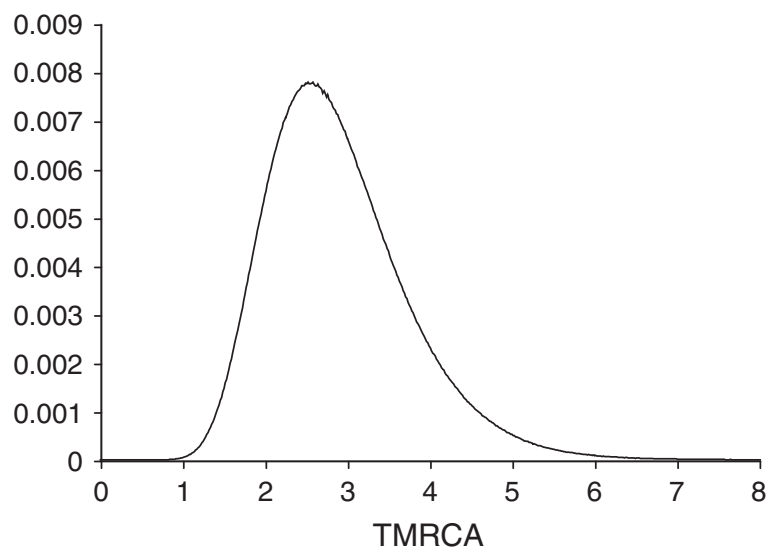

Figure 4 Posterior distributions from the program IM for parameter estimates from the Central (CA) and South American (SA) hook-billed kite Chondrohierax uncinatus population pairwise comparisons. The distributions are plotted for (a) female effective population size parameters for the Central American $\left(\theta_{\mathrm{CA}}\right)$ South American $\left(\theta_{\mathrm{SA}}\right)$ and the ancestral $\left(\theta_{\mathrm{A}}\right)$ populations, (b) migration parameter $(m)$, (c) the population divergence time parameter $(t)$ and $(d)$ the time to most recent common ancestor (TMRCA).

8000 , data not shown). Therefore, the upper portion of the posterior density for this parameter could not be determined; yet, the results do suggest that $\theta_{\mathrm{SA}}[82.6$; lower $95 \%$ highest posterior density (HPD): 38.1] is much larger than the same parameter estimate for Central America $\left(\theta_{\mathrm{CA}}=7.3 ; 95 \%\right.$ HPD: $\left.2.8-45.1\right)$ with little overlap in posterior densities, indicating a large difference in female effective population sizes between the two geographic areas (Fig. 4). The posterior distribution for $\theta_{\mathrm{A}}$ (effective size of the ancestral population) was similar (4.2; 95\% HPD: 0.8-88.3) to that given for Central America $\left(\theta_{\mathrm{CA}}\right)$ with posterior densities overlapping considerably, suggesting that the South American population has increased in size since population divergence, while the Central American population has not changed considerably since population divergence.

Estimates of migration rate $(m)$ between Central and South America using the program IM were varied, as the highest estimated density for $m$ was actually the lowestvalued bin (0.01), indicating little or no gene flow, and yet the $95 \%$ HPD was quite large, ranging from 0.01 to 12.8 (Fig. 4). This result might be due to historic migration events occurring relatively close in time to the actual divergence time, followed by isolation of the two populations, and this possibility is further supported by the upper bound for the posterior density for the population divergence parameter $t$ never reaching zero and becoming flat (see Fig. 4). Alternatively, it could be the result of too little information available within the dataset to determine accurately the amount of gene flow between the two populations (J. Hey, pers. comm.). The posterior distribution of population divergence $(t)$ peaked at 1.3 (95\% HPD: 0.5-4.6+), which corresponds to 25000-78 000 years, and time to most recent common ancestor (TMRCA) at 2.6 (95\% HPD: 1.6-4.9), or 50000-156000years (while incorporating the range of mutation rates).

\section{Discussion}

Based on the criteria of reciprocal monophyly, only two of the currently recognized hook-billed kite taxa (C. u. wilsonii and uncinatus) are supported in our mtDNA cyt $B$ and ND2 phylogeny. The two unique haplotypes from Cuba formed a strongly supported clade with high bootstrap and posterior 
probability (100 and 1.00, respectively, Fig. 2), therefore supporting the recognition and taxonomic classification of the Cuban kite, as a distinct species ( $C$. wilsonii). We did not observe monophyly for any of the remaining three subspecific taxa, suggesting that taxonomic revisions may be necessary. However, we did find genetic differences among other groups, suggesting recent divergence with limited or no gene flow (i.e. incomplete lineage sorting; see Avise, 2004; Omland, Baker \& Peters, 2006). Coalescent-based methods that focus on determining specific parameters associated with demographic history (e.g. $\theta$ and $m$ ) can be helpful for investigating the distinctiveness of populations in cases where divergences are more recent and reciprocal monophyly has not yet been achieved (Arbogast et al., 2002; Rosenberg \& Nordborg, 2002; Hey \& Machado, 2003). This information can prove useful to help identify evolutionary distinct lineages and clarify conservation priorities for the genus Chondrohierax.

\section{Island taxa differentiation}

The degree of differentiation differs substantially when comparing the two island hook-billed kite taxa (C. $u$. wilsonii and mirus) with the mainland taxa. Based on our estimates, the Cuban kite (C. u. wilsonii) has been isolated from other hook-billed kite populations since the MidPleistocene (400 000 years -1.25 million years), during which its unique yellow bill color evolved. Another recent study documented comparable divergence estimates for avian taxa having similar geographic distributions. Fleischer et al. (2006) estimated mtDNA divergences of 0.8-1.6 million years between three woodpecker taxa: the Cuban (Campephilus principalis bairdii) and North America (Campephilus principalis principalis) subspecies of ivory-billed woodpecker, and the imperial woodpecker Chondrohierax imperialis from Mexico. They also indicated that a divergence date $c .1$ million years ago corresponded with a period of global cooling and lowered sea levels, suggesting that dispersal from the Yucatan Peninsula to Cuba was possible because the distance between the two landmasses would have been much less than observed today $(\sim 176 \mathrm{~km})$. The hook-billed kite may also have colonized Cuba during this same time period, subsequently becoming isolated as sea levels increased and the distance between the two landmasses increased.

In contrast, the Grenada hook-billed kite $C$. $u$. mirus shows much less distinctiveness in both genetic and morphological characters relative to mainland hook-billed kites, although both island taxa are smaller in overall body size and have less variability in bill size and plumage coloration (Friedmann, 1934; Smith \& Temple, 1982a; Ferguson-Lees \& Christie, 2001). Although reciprocal monophyly is not supported for the Grenada hook-billed kite based on MP and Bayesian analyses (Fig. 2), the six birds sampled from Grenada do possess a unique mtDNA haplotype not observed elsewhere among sampled hook-billed kites. This unique haplotype is one to two nucleotide substitutions different from those observed among South American hook-billed kites (Fig. 3), suggesting that these two groups have diverged fairly recently (20000-190000 years); however, any inference based on this divergence estimate should be made with caution because it was calculated with a small sample size and limited sampling from proximate locations (Venezuela, $n=3$; Surinam, $n=2$ ) relative to Grenada (see Funk \& Omland, 2003 for sampling related issues). Hookbilled kites, although once present, no longer exist on the island of Trinidad (Ferguson-Lees \& Christie, 2001). This population, and possibly another on Tobago, would have been likely stepping-stones for colonizing or dispersing to Grenada from the mainland. The current geographic distance from Venezuela to Grenada $(\sim 160 \mathrm{~km})$ being similar to that observed between Cuba and the Yucatan peninsula $(\sim 176 \mathrm{~km})$ suggests that this distance may be large enough to limit dispersal between the two areas. Additional sampling from Venezuela and surrounding countries is needed to fully establish the genetic distinctiveness of this taxon.

\section{Mainland taxa differentiation}

No statistical support was observed for the identification of C. $u$. aquilonis in western Mexico as a distinct taxon (Figs 2 and 3), as one of the two mtDNA haplotypes for the two sampled individuals was also observed in four individuals identified as the nominate $C$. u. uncinatus collected elsewhere in Central America (southern Mexico, Costa Rica and Nicaragua; see Fig. 3). Unlike the Cuban and Grenada hook-billed kite populations, no obvious barrier in Mexico exists between aquilonis and uncinatus, with the exception of the lowlands of Istmo de Tehuantepec to the south-east of the proposed boundary (see Friedmann, 1934). Our data, however, do not support that this feature has functioned as a historic barrier to dispersal for these two currently recognized taxa (see also Peterson et al., 2004). Smith \& Temple (1982a) have also questioned the subspecies designation aquilonis based on the lack of consistent differences in male plumage characters that were originally used to describe this subspecies (see Friedmann, 1934).

We did, however, find support for two separate groups within the nominate taxon, $C . u$. uncinatus, a subdivision that has not been proposed prior to this study. When we classified haplotypes based on whether they were sampled from Central or South America, we observed that neither area shares haplotypes. Good support for a clade consisting of the majority of individuals collected from Central America, with the exception of two birds from Panama, was observed with our mtDNA dataset using MP and Bayesian analyses (Fig. 2). The same two Panamanian hook-billed kites, although possessing unique haplotypes, were intermixed with haplotypes from South America in a medianjoining network (Fig. 3). These two haplotypes from Panama may represent ancestral polymorphisms as they differed by five to six nucleotide substitutions from another hook-billed kite sampled from the same general location (Panama Canal) that clustered with the remaining Central American haplotypes. 
To further determine whether the association of haplotypes between Central and South America was due to incomplete lineage sorting or recent gene flow, we used the program IM to investigate the demographic history of hook-billed kites from these two populations. Based on these analyses, the data suggest that much of the observed genetic diversity observed in mainland hook-billed kites was present before the divergence of Central and South American populations ( $t$ vs. TMRCA). This would suggest, therefore, that little or no female-mediated gene flow has occurred between Central and South America since population divergence, and incomplete lineage sorting, rather than recent gene flow, is a more likely scenario for describing the association of haplotypes between these two populations (see also Peters, Gretes \& Omland, 2005; Omland et al., 2006). In contrast, if recent or ongoing gene flow were common between Central and South American hook-billed kites, then we would expect to observe shared haplotypes that are proportional to the frequencies observed in each area. Of course, these results are dependent on sampling and various assumptions made by the IM model (e.g. constant population size; Hey \& Nielsen, 2004), and it would be worth exploring further the divergence and estimates of migration between these two areas with additional genetic loci (e.g. Carstens \& Knowles, 2007) and methods (e.g. Maddison \& Knowles, 2006), provided that additional samples can be obtained.

\section{Conservation implications}

Ultimately, the time necessary to reach reciprocal monophyly is dependent on a number of factors. Most importantly, the effective size of a population $\left(N_{\mathrm{e}}\right)$ will determine the rate at which alleles, or haplotypes, become fixed through the random process of genetic drift (Tajima, 1983; Wakeley, 2000; Rosenberg, 2003). Eventually, all isolated populations will reach reciprocal monophyly, and generally, these populations should follow a predictable series of steps before achieving monophyly as long as isolation has been maintained (see Avise, 2004; Omland et al., 2006). The achievement of monophyletic status has significant conservation implications, as many researchers and managers currently recognize this condition as important for both taxonomic purposes and prioritizing conservation efforts (Moritz, 1994; Zink, 2004; Phillimore \& Owens, 2006), although, due to the stochastic nature associated with the coalescent process, the achievement of reciprocal monophyly is not absolute for describing evolutionary distinctiveness (Arbogast et al., 2002; Rosenberg \& Nordborg, 2002; Rosenberg, 2007), and other criteria, such as behavioral or ecological differentiation, may often be as important for delimiting taxonomic boundaries (see Fraser \& Bernatchez, 2001; Goldstein et al., 2005; Haig et al., 2006).

The Cuban kite has reached reciprocal monophyly based on this mtDNA dataset, a condition that was likely influenced by founder effects and its small effective population size as evident by its reduced variability in morphological characters (i.e. bill size and plumage coloration) and low haplotype diversity, a condition often observed among island taxa (Frankham, 1997). Similarly, the hook-billed kites sampled from Grenada possessed a single unique mtDNA haplotype and reduced variability in morphological characters, although this population is not as divergent as that observed with the Cuban kite, a difference that is likely associated with overall time in isolation. Reduced levels of variability within the Cuba and Grenada populations may make them more vulnerable to extinction (Spielman, Brook \& Frankham, 2004) and a high-priority concern for conservation. Unfortunately, the Cuban kite may already be extinct (Garrido \& Kirkconnell, 2000), and, although the Grenada kite population was thought to be extinct (Smith \& Temple, $1982 b)$, it is currently very small ( 40-50 individuals; Thorstrom et al., 2001).

In contrast, the mainland populations (i.e. Central and South America) have much higher levels of both morphological and mtDNA genetic variability compared with the two island populations. Although no observed mtDNA haplotypes were shared between hook-billed kites collected in either Central or South America, we did observe an intermixing of haplotypes between the two areas (Fig. 3). This would suggest that these two populations are in the process of moving toward monophyly but are currently at local fixation, or at allotypy, an intermediate stage of polyphyly (see Omland et al., 2006); however, this conclusion should be substantiated with additional sampling including further analyses before any taxonomic recommendations are made concerning this potential genetic subdivision between these two areas. Hook-billed kites on the mainland may also be experiencing significant declines, most likely related to changes in habitat, reduced snail abundances and direct persecution from humans (Ferguson-Lees \& Christie, 2001). Here, we have shown that subdivision may exist between Central and South American populations and based on estimated differences in effective population sizes using the program IM, the Central American population may be more vulnerable to extinction. Certainly, fewer haplotypes were observed with this population compared with South America.

The extreme variability in bill size and plumage coloration, at least for the mainland populations, is likely related to their effective population size, either being necessary for the development of this variability or a consequence of intraspecific variation in niche occupancy (i.e. snail size preferences), thereby allowing a larger population size to occur (e.g. disruptive selection; Smith \& Temple 1982a; Galeotti \& Rubolini, 2004; Rueffler et al., 2006). Hookbilled kites are specialized feeders and the removal, or harvesting, of snails has likely contributed to their decline. Based on our results, genetic subdivisions are supported for the populations on Cuba and Grenada and possibly between Central and South America indicating long-term dispersal barriers, which further reduce the effective sizes of each of these populations.

Chondrohierax represents a unique evolutionary history with a long phylogenetic branch-length relative to other taxa in the family Accipitridae (Lerner \& Mindell, 2005), and this 
lineage may be particularly vulnerable to extinction (see Purvis et al., 2000; Heard \& Mooers, 2002; Mace, Gittleman $\&$ Purvis, 2003). Abundance levels may continue to decline as habitats fragment and additional dispersal barriers develop (e.g. Johnson et al., 2004), and loss of bill size variation may limit resource allocation (e.g. Grant \& Grant, 2002). More research is needed to assess life-history constraints for this group and to help maintain viable populations in a rapidly changing landscape (Sodhi, Liow \& Bazzaz, 2004; Hoekstra et al., 2005; Davies et al., 2006).

\section{Acknowledgements}

We thank Desmond McQueen for his help in the field in Grenada, and gratefully acknowledge the following institutions for helping provide samples for this study: Field Museum of Natural History, Chicago; Museum of Comparative Zoology, Harvard University; National Museum of Natural History, Washington, DC; and University of Michigan Museum of Zoology, Ann Arbor. We are also grateful to Matthew Klaver for assisting in the laboratory, to Bill Burnham and Rick Watson for support and encouragement to complete this study and to Heather Lerner and two anonymous reviewers for providing helpful comments on this paper. This work was funded by The Peregrine Fund with additional support from the University of Michigan Museum of Zoology Bird Division.

\section{References}

Agapow, P.-M., Bininda-Edmonds, O.R.P., Crandall, K.A., Gittleman, J.L., Mace, G.M., Marshall, J.C. \& Purvis, A. (2004). The impact of species concept on biodiversity studies. Q. Rev. Biol. 79, 161-179.

Amadon, D. (1960). Notes on the genus Chondrohierax. Noved. Colombianas 1, 237-238.

Amadon, D. (1964). Taxonomic notes on birds of prey. Am. Mus. Novit. 2166, $2-3$.

Arbogast, B.S., Edwards, S.V., Wakeley, J., Beerli, P. \& Slowinski, J.B. (2002). Estimating divergence times from molecular data on phylogenetic and population genetic timescales. Annu. Rev. Ecol. Syst. 33, 707-740.

Avise, J.C. (2004). Molecular markers, natural history, and evolution. 2nd edn. Sunderland, MA: Sinauer Associates Ltd.

Bandelt, H.-J., Forster, P. \& Röhl, A. (1999). Median-joining networks for inferring intraspecific phylogenies. Mol. Biol. Evol. 16, 37-48.

Barker, G.M. (2002). Phylogenetic diversity: a quantitative framework for measurement of priority and achievement in biodiversity conservation. Biol. J. Linn. Soc. 76, 165-194.

Brown, L. \& Amadon, D. (1968). Hawks, eagles, and falcons of the world. Vol. 1. New York: McGraw-Hill Book Company.

Bunce, M., Szulkin, M., Lerner, H.R.L., Barnes, I., Shapiro, B., Cooper, A. \& Holdaway, R.N. (2005). Ancient DNA provides new insights into the evolutionary history of New Zealand's extinct giant eagle. PLoS Biol. 3, e9.

Carstens, B.C. \& Knowles, L.L. (2007). Shifting distributions and speciation: species divergence during rapid climate change. Mol. Ecol. 16, 619-627.

Cooper, A. \& Poinar, H. (2000). Ancient DNA: do it right or not at all. Science 289, 1139.

Davies, R.G., Orme, C.D.L., Olson, V., Thomas, G.H., Ross, S.G., Ding, T.-S., Rassmussen, P.C., Stattersfield, A.J., Bennett, P.M., Blackburn, T.M., Owens, I.P.F. \& Gaston, K.J. (2006). Human impacts and the global distribution of extinction risk. Proc. Roy. Soc. Lond. Ser. B-Biol. Sci. 273, 2127-2133.

Ferguson-Lees, J. \& Christie, D.A. (2001). Raptors of the world. London: Christopher Helms.

Fleischer, R.C., Kirchman, J.J., Dumbacher, J.P., Bevier, L., Dove, C., Rotzel, N.C., Edwards, S.V., Lammertink, M., Miglia, K.L. \& Moore, W.S. (2006). Mid-Pleistocene divergence of Cuban and North American ivory-billed woodpeckers. Biol. Lett. 2, 466-469.

Frankham, R. (1997). Do island populations have less genetic variation than mainland populations? Heredity $\mathbf{7 8}$, 311-327.

Fraser, D.J. \& Bernatchez, L. (2001). Adaptive evolutionary conservation: towards a unified concept for defining conservation units. Mol. Ecol. 10, 2741-2752.

Friedmann, H. (1934). The hawks of the genus Chondrohierax. J. Washington Acad. Sci. 24, 310-318.

Funk, D.J. \& Omland, K.E. (2003). Species-level paraphyly and polyphyly: frequency, causes, and consequences, with insights from animal mitochondrial DNA. Annu. Rev. Ecol. Evol. Syst. 34, 397-423.

Galeotti, P. \& Rubolini, D. (2004). The niche variation hypothesis and the evolution of colour polymorphism in birds: a comparative study of owls, nightjars and raptors. Biol. J. Linn. Soc. 82, 237-248.

Gamauf, A., Gjershaug, J.-O., Røv, N., Kvaløy, K. \& Haring, E. (2005). Species or subspecies? The delimma of taxonomic ranking of some south-east Asian hawk-eagles (genus Spizaetus). Bird Conserv. Int. 15, 99-117.

Garrido, O.H. \& Kirkconnell, A. (2000). Field guide to the birds of Cuba. Ithaca, NY: Cornell University Press.

Gilbert, M.T., Bandelt, H.J., Hofreiter, M. \& Barnes, I. (2005). Assessing ancient DNA studies. Trends Ecol. Evol. 20, 541-544.

Goldstein, P., Wyner, Y., Doukakis, P., Egan, M.G., Amato, G., Rosenbaum, H. \& DeSalle, R. (2005). Theory and methods for diagnosing species and populations in conservation. Ann. Mo. Bot. Gard. 92, 12-27.

Grant, P.R. \& Grant, B.R. (2002). Unpredictable evolution in a 30-year study of Darwin's finches. Science 296, 707-711.

Haig, S.M., Beever, E.A., Chambers, S.M., Draheim, H.M., Dugger, B.D., Dunham, S., Elliott-Smith, E., Fontaine, J.B., Kesler, D.C., Knaus, B.J., Lopes, I.F., Loschl, P., Mullins, T.D. \& Sheffield, L.M. (2006). Taxonomic 
considerations in listing subspecies under the U.S. Endangered Species Act. Conserv. Biol. 20, 1584-1594.

Hasegawa, M., Kishino, H. \& Yano, T. (1985). Dating of the human-ape splitting by a molecular clock of mitochondrial DNA. J. Mol. Evol. 21, 160-174.

Heard, S.B. \& Mooers, A.Ø. (2002). Signatures of random and selective mass extinctions in phylogenetic tree balance. Syst. Biol. 51, 889-897.

Helbig, A.J., Kocum, A., Seibold, I. \& Braun, M.J. (2005). A multi-gene phylogeny of aquiline eagles (Aves: Accipitriformes) reveals extensive paraphyly at the genus level. Mol. Phylogenet. Evol. 35, 147-164.

Hellmayr, C.E. \& Conover, B. (1949). Catalog of birds of the Americas. Publ. Field Mus. Nat. Hist. Zool. Ser. 13 pt. 1, no. 4.

Hendry, A.P., Vamosi, S.M., Latham, S.J., Heilbuth, J.C. \& Day, T. (2000). Questioning species realities. Conserv. Genet. 1, 67-76.

Hey, J. (2006). On the failure of modern species concepts. Trends Ecol. Evol. 21, 447-450.

Hey, J. \& Machado, C.A. (2003). The study of structure populations - new hope for a difficult and divided science. Nat. Rev. Genet. 4, 535-543.

Hey, J. \& Nielsen, R. (2004). Multilocus methods for estimating population sizes, migration rates and divergence time, with applications to the divergence of Drosophila pseudoobscura and D. persimilis.. Genetics 167, 747-760.

Hey, J., Waples, R.S., Arnold, M.L., Butlin, R.K. \& Harrison, R.G. (2003). Understanding and confronting species uncertainty in biology and conservation. Trends Ecol. Evol. 18, 597-603.

Ho, S.Y.W. \& Larson, G. (2006). Molecular clocks: when times are a-changin'. Trends Genet. 22, 79-83.

Hoekstra, J.M., Boucher, T.M., Ricketts, T.H. \& Roberts, C. (2005). Confronting a biome crisis: global disparities of habitat loss and protection. Ecol. Lett. 8, 23-29.

del Hoyo, J., Elliot, A. \& Sargatal, J. (Eds). (1994). Handbook of the birds of the world. Vol. 2. Barcelona: Lynx Edicions.

Hudson, R.R. \& Coyne, J.A. (2002). Mathematical consequences of the genealogical species concept. Evolution 56, $1557-1565$.

Johnson, J.A., Bellinger, M.R., Toepfer, J.E. \& Dunn, P.O. (2004). Temporal changes in allele frequencies and low effective population size in greater prairie-chickens. Mol. Ecol. 13, 2617-2630.

Johnson, J.A., Lerner, H.R.L., Rasmussen, P.C. \& Mindell, D.P. (2006). Systematics within Gyps vultures: a clade at risk. BMC Evol. Biol. 6, 65.

Johnson, J.A., Watson, R.T. \& Mindell, D.P. (2005). Prioritizing species conservation: does the cape verde kite exist? Proc. Roy. Soc. Lond. Ser. B-Biol. Sci. 272, 1365-1371.

Lerner, H.R.L. \& Mindell, D.P. (2005). Phylogeny of eagles, Old World vultures, and other Accipitridae based on nuclear and mitochondrial DNA. Mol. Phylogenet. Evol. 37, 327-346.
Lovette, I.J. (2004). Mitochondrial dating and mixed support for the " $2 \%$ rule" in birds. Auk 121, 1-6.

Mace, G.M. (2004). The role of taxonomy in species conservation. Philos. Trans. Roy. Soc. Lond. B-Biol. Sci. 359, 711-719.

Mace, G.M., Gittleman, J.L. \& Purvis, A. (2003). Preserving the tree of life. Science 300, 1707-1709.

Maddison, W.P. \& Knowles, L.L. (2006). Inferring phylogeny despite incomplete lineage sorting. Syst. Biol. 55, 21-30.

Moritz, C. (1994). Defining 'evolutionary significant units' for conservation. Trends Ecol. Evol. 9, 373-375.

Nylander, J.A.A. (2004). Mr.ModelTest v2.2. Program distributed by the author, Evolutionary Biology Centre, Uppsala University.

Omland, K.E., Baker, J.M. \& Peters, J.L. (2006). Genetic signatures of intermediate divergence: population history of old and new world holarctic ravens (Corvus corax). Mol. Ecol. 15, 795-808.

Peters, J.L. (1931). Checklist of birds of the world. Vol. 1, 1st edn. Cambridge, MA: Harvard University Press.

Peters, J.L. (1979). Checklist of birds of the world. Vol. 1, 2nd edn. Cambridge, MA: Harvard University Press.

Peters, J.L., Gretes, W. \& Omland, K.E. (2005). Late Pleistocene divergence between eastern and western populations of wood ducks (Aix sponsa) inferred by the 'isolation with migration' coalescent method. Mol. Ecol. 14, 3407-3418.

Peterson, A.T., Márquez, L.C., Jiménez, J.L.C., EscalonaSegura, G., Flores-Villela, O., García-López, J., Hernández-Baños, B., Ruiz, C.A.J., León-Paniagua, L., Amaro, S.M., Navarro-Sigüenza, A.G., Sánchez-Cordero, V. \& Willard, D.E. (2004). A preliminary biological survey of Cerro Piedra Larga, Oaxaca, Mexico: birds, mammals, reptiles, amphibians and plants. Ann. Inst. Biol. Ser. Zool. 75, 439-466.

Phillimore, A.B. \& Owens, I.P.F. (2006). Are subspecies useful in evolutionary and conservation biology? Proc. Roy. Soc. Lond. B - Biol. Sci. 273, 1049-1053.

Purvis, A., Agapow, P.-M., Gittleman, J.L. \& Mace, G.M. (2000). Nonrandom extinction and the loss of evolutionary history. Science 288, 328-330.

Purvis, A., Gittleman, J.L. \& Brooks, T. (Eds). (2005). Phylogeny and conservation. London: Cambridge University Press.

de Queiroz, K. (2005). Different species problems and their resolution. BioEssays 27, 1263-1269.

Raffaele, H., Wiley, J., Garrido, O., Keith, A. \& Raffaele, J. (1998). Birds of the West Indies. London: Christopher Helm Ltd.

Ronquist, F. \& Huelsenbeck, J.P. (2003). MrBAYEs 3: Bayesian phylogenetic inference under mixed models. Bioinformatics 19, 1572-1574.

Rosenberg, N.A. (2003). The shapes of neutral gene genealogies in two species: probabilities of monophyly, paraphyly, and polyphyly in a coalescent model. Evolution $\mathbf{5 7}$, 1465-1477. 
Rosenberg, N.A. (2007). Statistical tests for taxonomic distinctiveness from observations of monophyly. Evolution $\mathbf{6 1}$, 317-323.

Rosenberg, N.A. \& Nordborg, M. (2002). Genealogical trees, coalescent theory and the analysis of genetic polymorphisms. Nat. Rev. Genet. 3, 380-390.

Rozas, J., Sánchez-De, I., Barrio, J.C., Messeguer, X. \& Rozas, R. (2003). DNASP, DNA polymorphism analyses by the coalescent and other methods. Bioinformatics 19, 2496-2497.

Rueffler, C., Van Dooren, T.J.M., Leimar, O. \& Abrams, P.A. (2006). Disruptive selection and then what? Trends Ecol. Evol. 21, 238-245.

Sites, J.W. \& Marshall, J.C. (2004). Operational criteria for delimiting species. Annu. Rev. Ecol. Evol. Syst. 35, 199-227.

Smith, T.B. \& Temple, S.A. (1982a). Feeding habits and bill polymorphism in hook-billed kites. Auk 99, 197-207.

Smith, T.B. \& Temple, S.A. (1982b). Grenada hook-billed kites: recent status and life history notes. Condor $\mathbf{8 4}$, 131.

Sodhi, N.S., Liow, L.H. \& Bazzaz, F.A. (2004). Avian extinction from tropical and subtropical forests. Annu. Rev. Ecol. Evol. Syst. 35, 323-345.

Spielman, D., Brook, B.W. \& Frankham, R. (2004). Most species are not driven to extinction before genetic factors impact them. Proc. Natl. Acad. Sci. USA 101, 15261-15264.

Stotz, D.F., Fitzpatrick, J.W., Parker, T.A. \& Moskovits, D.K. (1996). Neotropical birds: ecology and conservation. Chicago: University of Chicago Press.
Swofford, D.L. (2003). PAUP*, phylogenetic analysis using parsimony ( ${ }^{*}$ and other methods). 4th edn. Sunderland, MA: Sinauer.

Tajima, F. (1983). Evolutionary relationship of DNA sequences in finite populations. Genetics 105, 437-460.

Thorstrom, R., Massiah, E. \& Hall, C. (2001). Nesting biology, distribution, and population estimate of the Grenada hook-billed kite Chondrohierax uncinatus mirus. Car. J. Sci. 37, 278-281.

Wakeley, J. (2000). The effects of subdivision on the genetic divergence of populations and species. Evolution 54, 1092-1101.

Zink, R.M. (2004). The role of subspecies in obscuring avian biological diversity and misleading conservation policy. Proc. Roy. Soc. Lond. Ser. B-Biol. Sci. 271, 561-564.

\section{Supplementary material}

The following material is available for this article online:

Table S1 Sample information for Chondrohierax uncinatus taxa used in this study.

Table S2 Primers used for the amplification of mtDNA cytB and ND2 in Chondrohierax taxa.

This material is available as part of the online article from http://www.blackwell-synergy.com/doi/abs/10.1111/ j.1469-1795.2007.00118.x

Please note: Blackwell Publishing are not responsible for the content or functionality of any supplementary materials supplied by the authors. Any queries (other than missing material) should be directed to the corresponding author for the article. 